\title{
The Genetics of 3-M Syndrome: Unravelling a Potential New Regulatory Growth Pathway
}

\author{
Dan Hanson $^{\mathrm{a}, \mathrm{b}}$ Philip G. Murray ${ }^{\mathrm{a}-\mathrm{c}}$ Graeme C.M. Black ${ }^{\mathrm{b}, \mathrm{c}}$ Peter E. Clayton ${ }^{\mathrm{a}, \mathrm{c}}$ \\ a Department of Endocrinology, and b ${ }^{b}$ enetic Medicine Research Group, Manchester Biomedical Centre, \\ Manchester Academic Health Sciences Centre, School of Biomedicine, University of Manchester, and \\ ${ }^{\mathrm{C} C e n t r a l}$ Manchester University Hospitals Foundation Trust, Manchester, UK
}

\section{Key Words}

Growth disorder $\cdot 3-\mathrm{M}$ syndrome $\cdot$ Silver-Russell syndrome $\cdot$ Ubiquitination $\cdot$ Insulin like growth factor signalling

\begin{abstract}
3-M syndrome is an autosomal recessive primordial growth disorder characterised by severe postnatal growth restriction caused by mutations in CUL7, OBSL1 or CCDC8. Clinical characteristics include dysmorphic facial features and fleshy prominent heels with a variable degree of radiological abnormalities. CUL7 is a structural protein central to the formation of an ubiquitin E3 ligase that is known to target insulin receptor substrate 1 for degradation. CUL7 also binds to p53 and may be involved in the control of p53-dependent apoptosis. OBSL1 is a cytoskeletal adaptor protein that was thought to play a central role in myocyte remodelling, and CCDC8 has no defined function as yet. However, the physical interaction of OBSL1 with both CUL7 and CCDC8 and its potential role in the regulation of CUL7 expression suggest all three proteins are members of the same growth-regulatory pathway. Future work should be directed to investigating the function of the 3-M syndrome pathway and in particular the role in the insulin like growth factor I signalling pathway with a view of potentially revealing new therapeutic targets and identifying key regulators of cellular growth.
\end{abstract}

Copyright $\odot 2011$ S. Karger AG, Basel

\section{KARGER}

Fax +4161306 1234 E-Mail karger@karger.ch www.karger.com

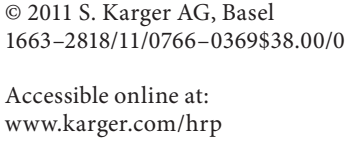

\section{Background: 3-M Syndrome and Differential Diagnosis}

The characterisation of disorders associated with extreme pre- and postnatal growth restriction allows the identification of novel human growth regulators. This has been demonstrated by studies of microcephalic osteodysplastic primordial dwarfism type II with the identification of mutations in pericentrin (PCNT), signifying the importance to human growth of the mitotic spindle in regulating normal chromosome segregation [1].

Through the study of molecular defects of the primordial growth disorder 3-M syndrome (MIM 273750 and 612921), we have identified a novel pathway controlling human growth. 3-M syndrome is a distinct growth disorder first described by Miller, McKusick and Malvaux in 1975 , with the name derived from the shared initial letter of the authors' surnames [2]. 3-M syndrome is characterised by prenatal growth restriction in the absence of recognisable maternal or placental pathology and by the failure of postnatal catch-up growth resulting in significant proportionate short stature without associated microcephaly often seen in microcephalic osteodysplastic primordial dwarfism type II.

Silver-Russell syndrome (SRS), a severe short stature condition with a high degree of phenotypic overlap with

Prof. P.E. Clayton

Department of Endocrinology, Manchester Academic Health Sciences Centre

School of Biomedicine, University of Manchester

Manchester M13 9WL (UK)

Tel. +44 161701 6949,E-Mail peter.clayton@manchester.ac.uk 
Table 1. Differential diagnosis between 3-M syndrome and SRS - a comparison of the typical clinical features [4-16]

\begin{tabular}{|c|c|}
\hline 3-M syndrome & SRS \\
\hline IUGR mean BW -3 SD & Asymmetric IUGR mean BW $-3.7 \mathrm{SD}$, mean $\mathrm{BL}-4 \mathrm{SD}$ \\
\hline Adult height in the range of -8 to $-4 \mathrm{SD}$ & Mean adult height of $-4.2 \mathrm{SD}$ \\
\hline Triangular face, full fleshy lips, frontal bossing, upturned fleshy nose & Triangular face, thin lips, frontal bossing \\
\hline Tall vertebral body, slender long bones & Limb asymmetry \\
\hline Normal intelligence & Variable incidence of learning difficulties \\
\hline Prominent heels & Normal heels \\
\hline Autosomal recessive & Genetically heterogeneous \\
\hline$\sim 65 \%$ CUL7 mutations & $\sim 50 \% 11 \mathrm{p} 15$ hypomethylation \\
\hline$\sim 30 \%$ OBSL1 mutations & $\sim 10 \%$ maternal uniparental disomy of chromosome 7 \\
\hline$\sim 5 \%$ CCDC8 mutations & $\sim 40 \%$ unknown cause \\
\hline
\end{tabular}

$\mathrm{BW}=$ Birth weight; $\mathrm{BL}=$ birth length.

3-M syndrome, should be considered in the differential diagnosis. There have been over 400 reported cases of SRS [3]. The key diagnostic characteristics of SRS include a birth weight $<-2$ standard deviation score (SDS), postnatal growth restriction, normal head circumference, triangular-shaped face with a broad forehead and a pointed, small chin with a wide, thin mouth and body asymmetry [4]. Patton [5] proposed that the slender long bones and tall vertebrae in 3-M syndrome are important in distinguishing between the two conditions. However, many 3-M syndrome patients do not show these features, suggesting that this should probably not be used for differential diagnosis. Learning difficulties can be a part of SRS but are not seen in 3-M syndrome, whereas prominent heels, a fleshy protrusion on the back of the heel, are an almost universal feature in 3-M syndrome patients but not in SRS patients (table 1).

\section{Genetics of Silver-Russell Syndrome}

SRS is genetically heterogeneous and often sporadic [17], and around $60 \%$ of cases are associated with genetic abnormalities: approximately $50 \%$ have imprinting abnormalities on chromosome 11p15, while approximately $10 \%$ demonstrate uniparental disomy of chromosome 7 (UPD7) [18].

Hypomethylation of the insulin like growth factor II (IGF-II) and H19 imprinting centre at $11 \mathrm{p} 15$ has recently been associated with SRS [19]. While loss of DNA methylation of this site results in an SRS phenotype, hypermethylation of the same site results in the overgrowth syndrome Beckwith-Wiedemann [19]. Eggermann et al.
[20], Gicquel et al. [21] and Eggermann [22] showed that a number of patients exhibiting an SRS phenotype have a maternal 11p15 duplication that leads to loss of IGF-II expression and concomitant short stature.

UPD7 involves maternal chromosome regions 7p12p14 and 7q31-qter [23]. The region at chromosome 7p12p14 contains a number of imprinted candidate genes including GRB10, IGFBP1 and IGFBP3. Mutation analysis of GRB10, however, has not revealed any pathogenic variants in SRS patients [3]. The causative gene in the region 7q31-qter has likewise not been identified [17].

\section{Clinical Features of 3-M Syndrome}

The main clinical features of 3-M syndrome are severe postnatal growth restriction with normal but recognisable facial features including triangular face, flat maxillae and prominent forehead. Other facial features include a fleshy tipped nose, pointed chin and long philtrum [2, $13,14]$. Skeletal abnormalities including relatively tall vertebrae and slender long bones are seen with variable frequency $[13,24,25]$. Other features commonly associated with 3-M syndrome are a short neck, winged scapulae, short thorax, transverse chest groove, hyperlordosis, developmental dysplasia hip and spina bifida occulta [2, $8,12-15,24-26]$. In younger patients, prominent heels are an almost universal feature, particularly in those with a genetic diagnosis. Unlike many other short stature conditions, 3-M syndrome is associated with normal intelligence and developmental milestones are achieved. Adult height is in the range of 115 to $150 \mathrm{~cm}(-8$ to $-4 \mathrm{SD})$ (fig. 1 ) [10]. 
Family 1 CCDC8 mutation

a $C .84$ ins T
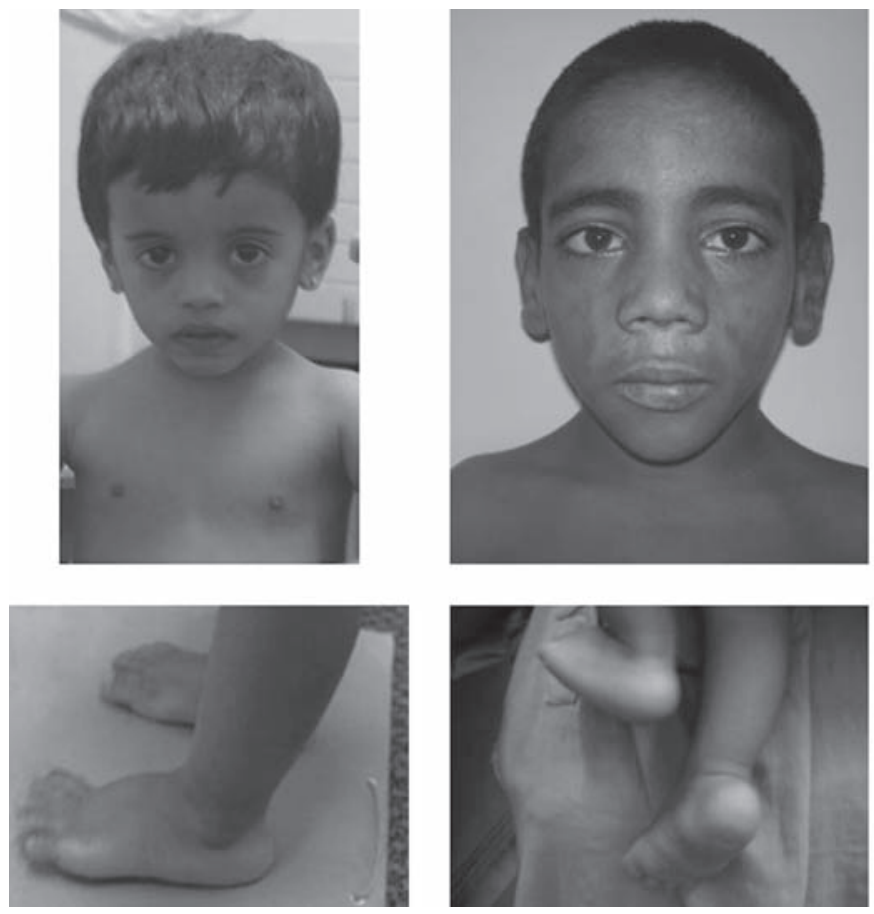

Fig. 1. Clinical features of 3-M syndrome individuals. a 3-M syndrome patient with a CCDC8 mutation. b, c Two 3-M syndrome families in which CUL7 mutations have been found. d A 3-M syndrome patient with an OBSL1 mutation. All patients have facial
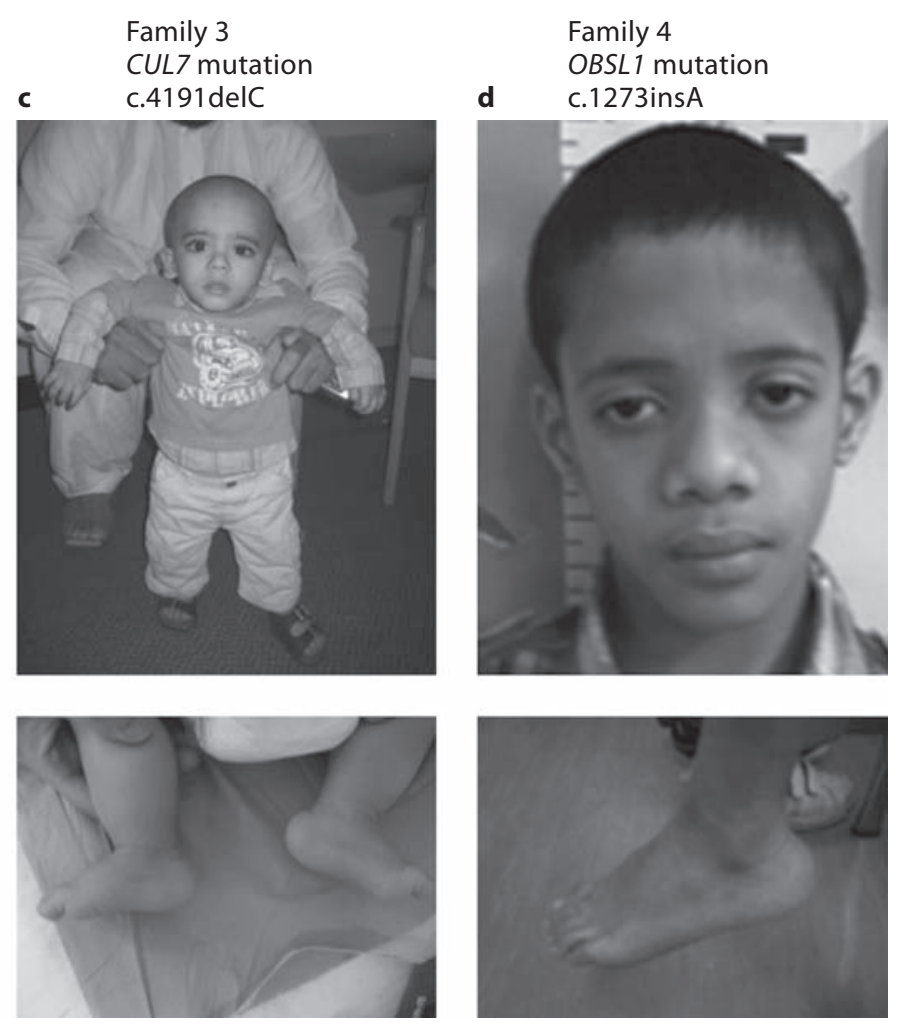

dysmorphism. Typical features include a triangular face, fleshy tipped nose, frontal bossing, midfacial hypoplasia and a pointed chin. Prominent heels are particular evident in younger 3-M syndrome patients.

\section{Genetics of 3-M Syndrome}

The initial 3-M syndrome locus was identified on $6 \mathrm{p} 21.1$, and subsequent candidate analysis of the region revealed that mutations in the cullin 7 gene (CUL7) cause 3 -M syndrome [10]. As part of that investigation, we identified a smaller subset of patients who did not carry CUL7 mutations but appeared to present with an identical phenotype (fig. 1). Further autozygosity mapping revealed a second locus located on 2q35 with mutations in the gene encoding for obscurin-like 1 (OBSL1) found to be the underlying cause [24]. In addition, a number of patients have neither CUL7 nor OBSL1 mutations, and exome sequencing in 3 such patients revealed that mutations in the coiled-coil domain containing protein 8 (CCDC8) cause the 3-M syndrome [27].

\section{CUL7 Mutations Cause 3-M Syndrome}

Huber et al. [10] performed autozygosity mapping with seven consanguineous 3-M syndrome families of Tunisian, Moroccan and French descent. This revealed a 3.84- $\mathrm{Mb}$ homozygous region shared by all seven families on chromosome $6 \mathrm{p} 21.1$. In addition, all four Tunisian families shared a $0.47-\mathrm{Mb}$ region of common haplotype indicating the location of the candidate gene. Subsequent analysis revealed pathogenic mutations within CUL7. CUL7 mutations are found throughout the whole gene, although approximately half of the mutations are located in the cullin domain. The majority of CUL7 mutations cause premature termination and are therefore likely to lead to complete loss of the CUL7 protein; however, a small number are missense mutations and thus predicted to lead to the generation of a nonfunctional protein product (fig. 2) [10, 25, 28].

3-M syndrome shares a high degree of similarity with two other short stature conditions: gloomy face syn- 


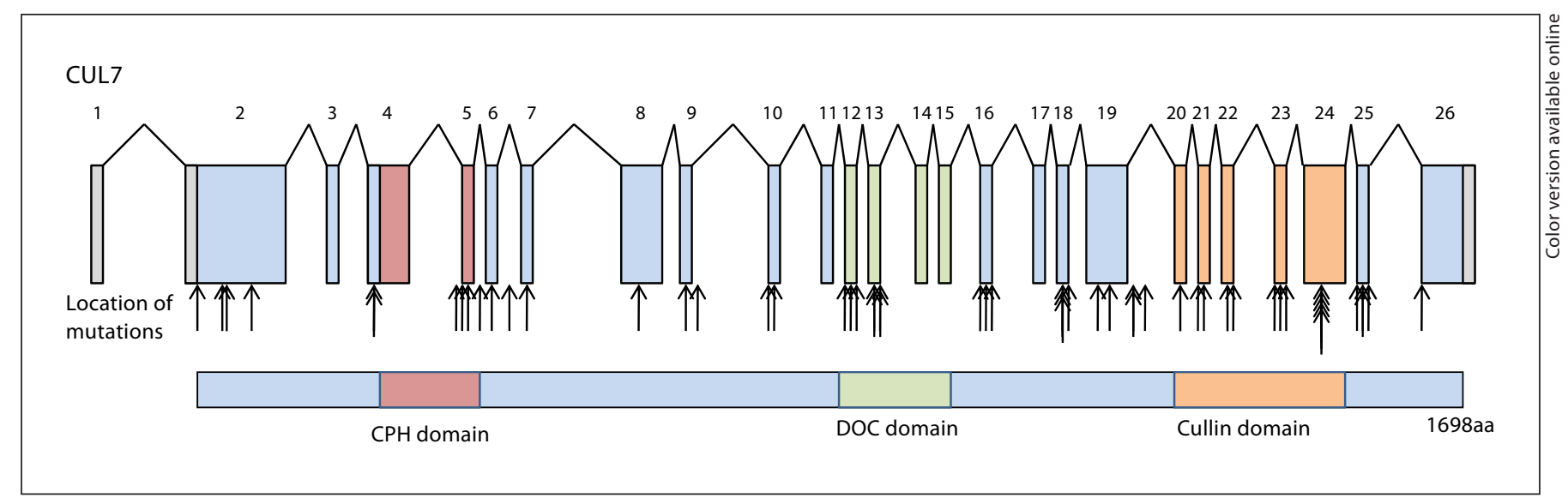

Fig. 2. Gene layout of CUL7. Intron and exon structure of CUL7 (non-coding UTRs are indicated by grey shading) with arrows indicating the location of known mutations and the location of the 3 main functional domains of CUL7 protein are shown.

drome [26] and the recently identified Yakut short stature syndrome [25]. Both have the same genetic cause as 3-M syndrome and are therefore unlikely to be separate entities, but rather to be part of a wider 3-M syndrome spectrum. Huber et al. [10] suggested the inclusion of gloomy face into 3-M syndrome following similarities in longterm follow-up and, most importantly, the identification of mutations in CUL7 in both sets of patient. Maksimova et al. [25] reported that the Yakut short stature syndrome patients suffered variable neonatal respiratory distress that had not been previously recognised as a feature of 3-M syndrome. However, other clinical features and characteristics of 3-M syndrome and identification of mutations in CUL7 would suggest that the Yakut short stature syndrome patients actually have 3-M syndrome.

\section{CUL7 and the Ubiquitin-Proteasome Pathway}

The protein product CUL7 is the most recently defined member of the cullin family and is an integral part of the ubiquitin-proteasome pathway acting as a structural protein in the formation of a SKP1-CUL7-FBXW8ROC1 (SCF) E3 ubiquitin ligase complex [29].

The ubiquitin-proteasome pathway is a major protein degradation pathway in which proteins are targeted for degradation, a process which involves attachment of ubiquitin to a target protein by the E3 ubiquitin ligase complex followed by degradation by the $26 \mathrm{~S}$ proteasome. The roles of SCF complexes and the ubiquitination system have been reviewed previously [30].
Unlike other cullin proteins which can interact with several F-box proteins to form alternative SCF complexes, FBXW8 is currently the only F-box protein known to interact with CUL7 (fig. 3). In keeping with the clinical feature of 3-M syndrome, targeted disruption of $\mathrm{Cul7}$ in mice resulted in intrauterine growth restriction (IUGR) and placental abnormalities. Arai et al. [31] showed that Cul $7^{-/-}$embryos survived to embryonic day 18.5 but did not survive birth. In addition to the severe growth restriction seen, $\mathrm{Cul}^{-1-}$ embryos were unable to breathe unaided, and it was shown that the lungs had markedly reduced alveolar space compared to wild type [31]. Although a 3-M syndrome foetus with a CUL7 mutation had no obvious alveolar abnormalities, there was insufficient development of the cartilaginous lamina, which may explain the respiratory distress that was seen in a subset of the Yakut 3-M syndrome patients [25]. The $\mathrm{Cul7}^{-1-}$ phenotype is similar to that exhibited by $\mathrm{Fb}_{\mathrm{W}} \mathrm{P}^{-\mathrm{I}^{-}}$mice with severe growth restriction and some respiratory failure [32]. $F b x w 8^{-/-}$mice have a reduced placental size but appear to have no isolated placental abnormalities. Tsutsumi et al. [33] confirmed the $F b x w 8^{-/-}$phenotype and underlined the similarities between $\mathrm{Fb} x w 8^{-/-}$ and $\mathrm{Cul7}^{-/-}$mice. Growth restriction of $\mathrm{Fbxw}^{-/-}$mice continued postnatally, but the mice were otherwise normal. Arai et al. [31] established that Fbxw8 protein levels were reduced in $\mathrm{Cul}^{-1-}$ cells, with Tsutsumi et al. [33] demonstrating that $\mathrm{Cul} 7$ levels were also reduced in $\mathrm{Fb} \mathrm{w} 8^{-/-}$mouse embryonic fibroblast (MEF) cells. $F b \times w 8^{-/-}$MEFs grew very poorly when compared to $\mathrm{Fbxw} 8^{+/-}$or $\mathrm{Fbxw} 8^{+/+} \mathrm{MEFs}$. The increased severity in the 
Fig. 3. CUL7 SCF complex. Schematic representation of the CUL7 SCF complex (E3 core in red) showing polyubiquitination of a substrate protein, which is then targeted for degradation by the $26 \mathrm{~S}$ proteasome leaving free ubiquitin and short peptides.

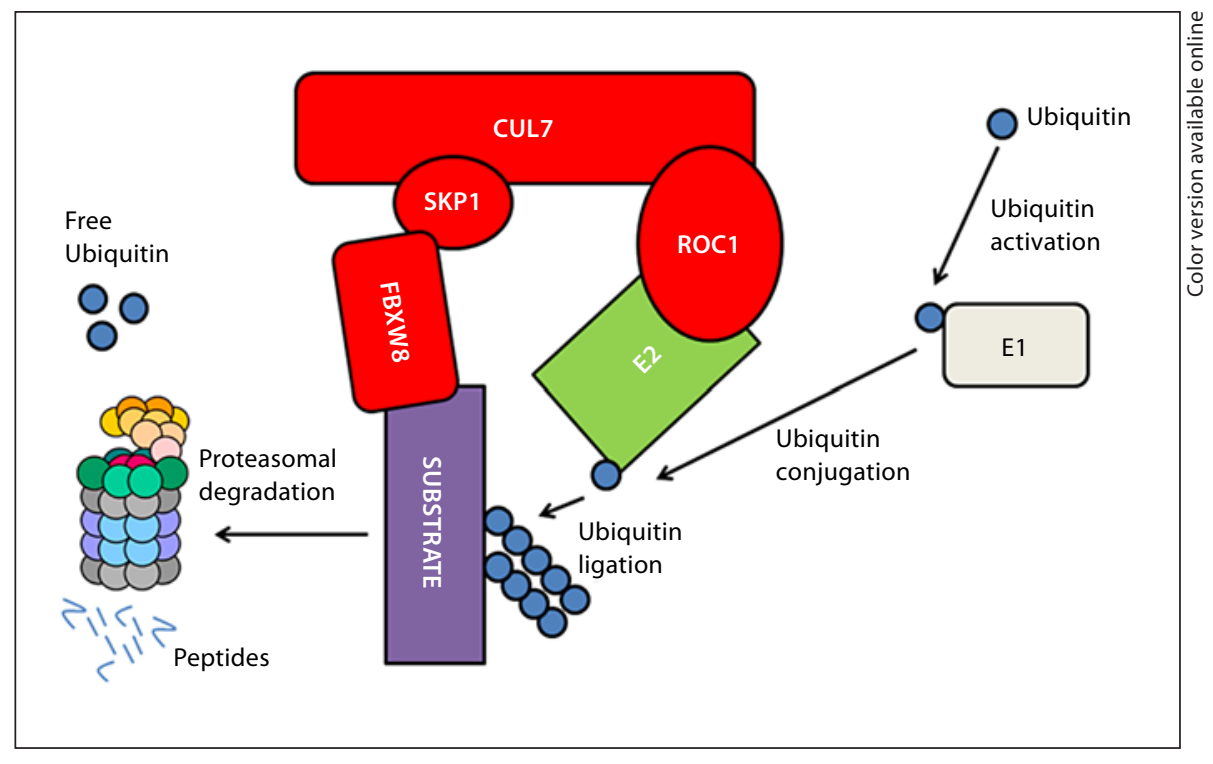

phenotype of mice which lack Cul7 compared to Fbxw8 is especially evident as $30 \%$ of $F b x w 8^{-/-}$mice survive birth. This would suggest that Cul7 has further cellular functions that are not shared with Fbxw8 $[32,34]$.

\section{CUL7 Interaction Network}

To date, there is limited data regarding the known proteolytic targets of the CUL7 SCF complex. Two studies have shown the F-box component of the CUL7 SCF complex, FBXW8 interacts with and targets the degradation of cyclin D1 [35] and insulin receptor substrate 1 (IRS-1) [36].

\section{Cyclin D1}

The role of cyclin D1 as an important regulator of cell cycle progression and its role in cancer due to aberrant expression have been previously reviewed [37]. Okabe et al. [35] demonstrated that cyclin D1 associates with FBXW8 - an interaction dependent on MAPK-mediated T286 phosphorylation suggesting that the CUL7 SCF complex is responsible for cyclin D1 ubiquitination. However, further evidence that multiple SCF complexes are responsible for cyclin D1 ubiquitination and subsequent degradation makes it difficult to determine the importance of FBXW8/CUL7-mediated cyclin D1 degradation to cell cycle regulation [38].

The Genetics of 3-M Syndrome

\section{IRS-1}

IRS-1 is a member of a family of proteins that act as adaptor proteins in both the insulin and IGF-I signalling cascades and are involved in numerous biological pathways [39]. In 2008, Xu et al. [36] performed a proteomic analysis to discover potential targets of the CUL7 SCF complex by using a stable FBXW8-expressing cell line to immunoprecipitate interacting partners and thus probable substrate proteins. This led to the identification of IRS-1 as a proteolytic target of the CUL7 SCF complex [36]. IRS-1 binds to the insulin or IGF-I receptors and is phosphorylated at the tyrosine-rich C-terminal region. $\mathrm{SH}-2$ domain-containing proteins are then recruited, leading to the activation of downstream pathways including AKT and MAPK/ERK [39]. Xu et al. [36] demonstrated that IRS-1 was polyubiquitinated in the presence of FBXW8, and this ubiquitination led to increased degradation of the IRS-1 protein. Using a mouse knockout model of $\mathrm{Cul}$, they showed in MEF cells from $\mathrm{Cul} 7^{-/-}$ mice that although the protein levels of Irs-1 increased dramatically in $\mathrm{Cul7^{-l- }}$ MEFs, mRNA expression of Irs-1 was not significantly altered between $\mathrm{Cul}^{-/-}$and $\mathrm{Cul} 7^{+/+}$ cells. In addition to the increased levels of Irs-1, Cul7 ${ }^{-1-}$ MEFs also grew very poorly when compared to $\mathrm{Cul7^{+/+ }}$ or $\mathrm{Cul7}^{+/-} \mathrm{MEFs}$, and the growth rate of the $\mathrm{Cul7^{-/ }}$ MEFs decreased over time. At passage 7, $\mathrm{Cul}^{-/-} \mathrm{MEFs}$ became flat and enlarged in comparison to $\mathrm{Cul7^{+/+ }}$ MEFs. This indicated that $\mathrm{Cul7}$ knockout may induce cellular senescence [36]. It is possible that accumulation

Horm Res Paediatr 2011;76:369-378 


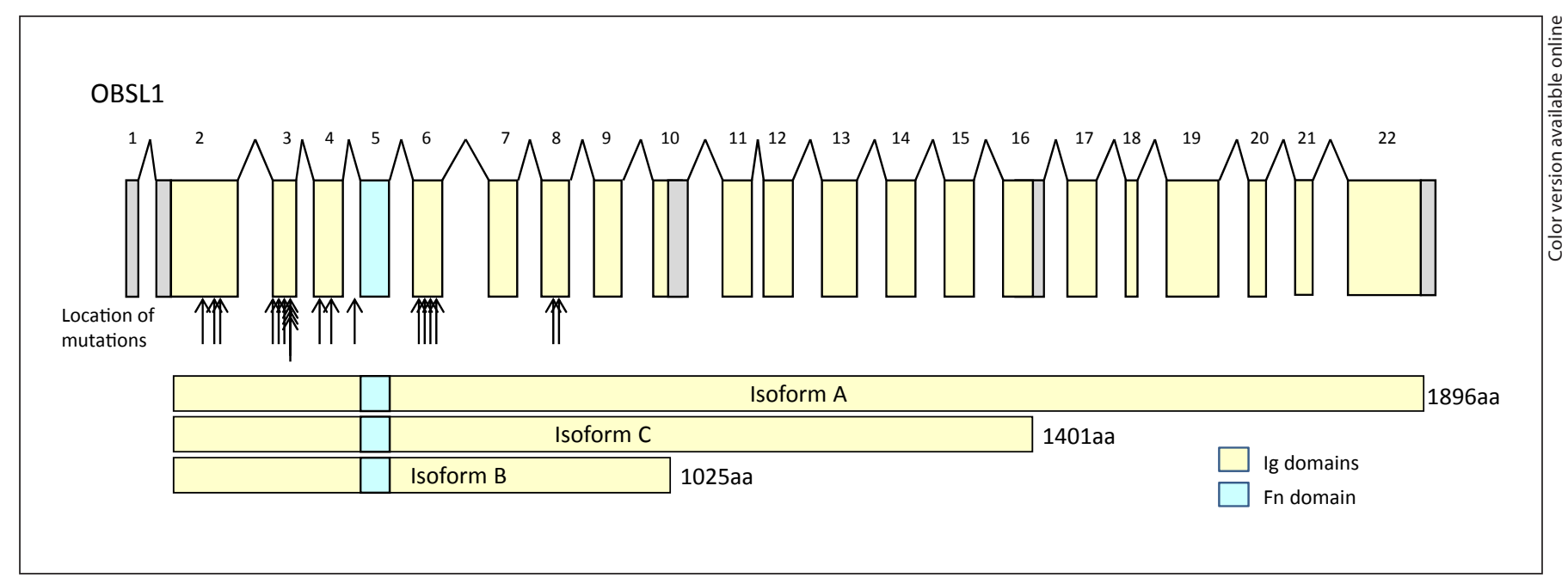

Fig. 4. Gene layout of OBSL1. Intron and exon structure of OBSL1 (non-coding UTRs are indicated by grey shading) with arrows indicating the location of known mutations clustered near the N-terminal region, thus affecting all 3 protein isoforms. The three isoforms arise from use of alternative stop codons in exons 10, 16 and 22 and encode for proteins with variable numbers of C-terminal Ig domains.

of IRS-1 may activate CUL7-mediated cellular senescence, which may in part explain the growth restriction seen in 3-M syndrome patients [36].

\section{Non-Proteolytic Function of CUL7}

Atypical of other cullin proteins, CUL7 also contains a $\mathrm{CPH}$ domain (a conserved region found in CUL7/ PARC/HERC2) [40]. This domain is responsible for some non-proteolytic functions of CUL7, including acting as a p53 binding region and, although the CUL7 E3 ligase is not responsible for the degradation of $\mathrm{p} 53$, it may participate in its activation and cellular localisation [40-43]. Whether CUL7 contributes to p53-dependent apoptosis remains to be fully determined; however, Kim et al. [44] demonstrated that CUL7 expression prevents c-Myc- and $\mathrm{N}$-Myc-mediated apoptosis in a p53-dependent manner.

\section{OBSL1 Mutations Cause 3-M Syndrome}

In a large cohort of 3-M syndrome patients who did not carry CUL7 mutations, we performed autozygosity mapping revealing a second 3-M syndrome locus located at chromosome 2q35-q36.1, spanning 5.7 Mb. Further haplotype analysis refined the critical region to a 1.27 $\mathrm{Mb}$ region. Pathogenic mutations were subsequently identified in the OBSL1 gene, of which all were presumptive null mutations [24]. Huber et al. [45] also identified OBSL1 mutations in a separate cohort of 3-M syndrome patients, including the identification of the first OBSL1 missense mutation (fig. 4).

To date, approximately $65 \%$ of mutations described in 3-M syndrome patients are found in CUL7, with $30 \%$ identified in OBSL1 $[10,24,25,28,45]$.

\section{OBSL1 Structure and Function}

OBSL1 is related to the giant muscle protein obscurin [46]. Gene duplication and rearrangement of obscurin resulted in the formation of two genes: SPEG (striated muscle preferentially expressed gene) and OBSL1. SPEG was first identified as a serine/threonine kinase with isoforms expressed in smooth, skeletal and heart muscle as well as brain tissue [47]. It was subsequently found that SPEG shared its arrangement of these kinase domains with obscurin [48]. OBSL1 was identified by Geisler et al. [46] and is located within $100 \mathrm{~kb}$ of SPEG on chromosome $2 \mathrm{q} 35$. The fibronectin domain of OBSL1 is most closely related to the fibronectin domain at the aminoterminal of obscurin [46]. Previously, Sutter et al. [48] showed that the carboxy fibronectin domain of obscurin closely resembled the fibronectin domain of SPEG. Also, SPEG is transcribed by the forward strand of chromo- 
some 2, whereas OBSL1 is transcribed by the reverse strand. Therefore, the duplication event of obscurin that gave rise to OBSL1 and SPEG also resulted in a genomic rearrangement.

OBSL1 exists as three groups of isoforms A, B and C that share a common translational start site which is also conserved between human, mouse and rat [46]. The variability of the three OBSL1 isoforms is derived from the use of alternative stop codons. Geisler et al. [46] identified a number of different transcripts ranging in size from 3.3 to $5.9 \mathrm{~kb}$. All OBSL1 isoforms share a common aminoterminal region consisting of four Ig domains and a fibronectin domain. The smaller transcripts encode three carboxy-terminal Ig domains, whereas the longest known transcript of isoform A encodes thirteen carboxy-terminal Ig domains [46]. Interestingly, Fukuzawa et al. [49] have suggested that further differentially spliced variants of OBSL1 exist. Three human expressed sequence tags have been identified in which the first coding exon is missing (DA680669, BX381924 and DA427488), suggesting the possible use of one of two alternative translational start sites located in exon 3, both in the same reading frame as the original translational start site. The potential new alternative translational start site residues would correspond to p.M413 and p.M479 of the current OBSL1 isoforms.

Cellular localisation studies carried out in adult rat cardiac myocytes revealed that OBSL1 is found at the intercalated discs, the perinuclear region and the $\mathrm{Z}$ lines with low level expression at the $M$ bands [46]. During remodelling of myocytes to form new sarcomeres, OBSL1 localises to the perinuclear region but dissociates from both the $\mathrm{Z}$ lines and $\mathrm{M}$ bands [46]. Geisler et al. [46] also suggested that OBSL1 remains associated with the nuclear envelope and surrounding cytoskeletal network, but that this is dependent on the morphology of the nucleus.

OBSL1 is composed entirely of Ig-like domains with a single fibronectin domain. These domains have been previously identified in titin, myomesin and obscurin in which they play a role in protein-protein interaction [46]. Due to the cellular localisation in cardiac myocytes and the predicted domain structure of OBSL1, Geisler et al. [46] postulated that OBSL1 may function as a cytoskeletal adaptor protein linking membrane-bound nuclear proteins to the cytoplasmic support network. Since Geisler et al. [46] also found that OBSL1 was expressed in a wide variety of cell types, it is possible that OBSL1 may have a broader role as a scaffolding protein. During the investigation by Fukuzawa et al. [49], the N-terminal region of obscurin was found to interact with both titin and myomesin; at the same time, interaction between these two proteins and OBSL1 was also established. Similar to obscurin, it was found that the $\mathrm{N}$-terminal region of OBSL1, which is homologous to the N-terminal region of obscurin, is also responsible for the interaction with titin and myomesin [49-51]. Fukuzawa et al. [49] assumed that since OBSL1 lacks any of the signalling domains of obscurin, its primary role would be as a structural protein.

Both Geisler et al. [46] and Fukuzawa et al. [49] postulated that the involvement of OBSL1 as a key component of the cytoskeletal network indicated a role in the progression of myopathies. Fukuzawa et al. [49] suggested that this would be due to loss of titin interaction at the M lines of sarcomeres. However, our recent report identifying OBSL1 mutations as a cause of 3-M syndrome indicated a broader role for OBSL1 in the CUL7 ubiquitination pathway [24]. Currently, there is only rudimentary knowledge of OBSL1 and it is clear that further characterisation is required to elucidate the function of OBSL1 and specifically its impact on the regulation of human growth. To date, we did not identify muscle weakness as a feature of 3-M syndrome.

\section{CCDC8 Mutations Cause 3-M Syndrome}

We and others have reported some cases of 3-M syndrome patients who have neither CUL7 nor OBSL1 mutations, suggesting involvement of further genes [24, 45]. We recently identified mutations in CCDC8 in a small cohort of 3-M syndrome patients. Two different mutations have so far been identified in five unrelated families and both result in the generation of a premature stop codon and subsequent loss of function. We demonstrated by immunoblotting that a 3-M syndrome patient with a CCDC8 mutation had no detectable CCDC8 protein and that 3-M syndrome patients with either CUL7 or OBSL1 mutations had normal levels of CCDC8 protein [27].

\section{Elucidating the 3-M Syndrome Pathway}

Thus, three apparently unrelated cytoplasmic proteins have been implicated in the pathogenesis of the human growth disorder 3-M syndrome: one an ubiquitin ligase (CUL7), one a cytoskeletal adaptor (OBSL1) and one a protein of undefined function (CCDC8). In the current 
literature, 94 families have a genetic confirmation of 3-M syndrome: 63 families have CUL7 mutations, 26 OBSL1 mutations and 5 CCDC8 mutations. We have previously shown that loss of OBSL1 by siRNA also leads to reduction of CUL7 expression, suggesting the two proteins may be linked [24]. However, it appears that the loss of either CUL7 or OBSL1 in patient-derived cells does not affect CCDC8 levels. Co-immunoprecipitation assays revealed that CCDC8 and OBSL1 physically interact, while, at the same time, OBSL1 and CUL7 interact; however, in this system CCDC8 and CUL7 do not appear to directly associate [27]. The identification of three different genes associated with the same growth disorder and the associated physical interactions between the three proteins would suggest that they exist within a common biochemical pathway.

\section{How Does Disruption of the CUL7/OBSL1 Pathway Lead to Growth Restriction?}

Murine models of $\mathrm{Cul7}$ and $\mathrm{Fbxw8}$ disruption exhibit an impairment of growth, and cell lines derived from these animal models demonstrate a reduction in cell proliferation and induction of senescence $[31,33,36]$. It is likely that the primary mechanism responsible for the growth restriction seen in knockout mouse models and in 3-M syndrome patients is the disruption of the CUL7 SCF complex. The downstream effects of this disruption result in a failure of IRS-1 ubiquitination and proteolysis, thus leading to cellular accumulation of IRS-1.

Alteration of the IGF-I pathway has long been shown to result in severe growth restriction in mouse knockout models [52-54]. The apparent accumulation of IRS-1 leads to the activation of the AKT and MAPK pathways. It is postulated that the overstimulation of these pathways ultimately leads to induction of cellular senescence [36], which in turn could result in poor growth explaining the growth restriction of 3-M syndrome patients.

Future studies should be directed at the identification of the remaining members of this pathway and how this novel pathway controls cell growth. For instance, it is currently unclear as to how OBSL1 interacts with the IGF-I signalling pathway; however, it may function as a structural protein linking CUL7 to IRS-1. The identification of further genes causing 3-M syndrome is likely to reveal other proteins in this pathway.

The importance of this pathway extends beyond human growth in that CUL7 has been implicated in cancer. It has been shown in a number of studies that the expression of SCF complexes, notably CUL1 (reviewed in [55]) and CUL7 [44], are elevated in a number of malignant tumours, but it may be that loss of CUL7 and/ or associated proteins is in fact cancer protecting. Thus, understanding the key interactions between CUL7, OBSL1, CCDC8 and IGF signalling may have implications both for statural grow th and dysregulated cellular growth.

\section{Acknowledgments}

Support from the National Institute of Health Research Manchester Biomedical Research Centre is acknowledged. P.G.M. is a Medical Research Council (UK) clinical research fellow.

\section{References}

$\checkmark 1$ Rauch A, Thiel CT, Schindler D, Wick U, Crow YJ, Ekici AB, van Essen AJ, Goecke TO, Al-Gazali L, Chrzanowska KH, Zweier C, Brunner HG, Becker K, Curry CJ, Dallapiccola B, Devriendt K, Dorfler A, Kinning E, Megarbane A, Meinecke P, Semple RK, Spranger S, Toutain A, Trembath RC, Voss E, Wilson L, Hennekam R, de Zegher F, Dorr HG, Reis A: Mutations in the pericentrin (PCNT) gene cause primordial dwarfism. Science 2008;319:816-819.

2 Miller JD, McKusick VA, Malvaux P, Temtamy S, Salinas C: The 3-M syndrome: a heritable low birthweight dwarfism. Birth Defects Orig Artic Ser 1975;11:39-47.

\footnotetext{
6
}

3 Abu-Amero S, Monk D, Frost J, Preece M, Stanier P, Moore GE: The genetic aetiology of Silver-Russell syndrome. J Med Genet 2008;45:193-199.

-4 Price SM, Stanhope R, Garrett C, Preece MA, Trembath RC: The spectrum of Silver-Russell syndrome: a clinical and molecular genetic study and new diagnostic criteria. J Med Genet 1999;36:837-842.

5 Patton MA: Russell-Silver syndrome. J Med Genet 1988;25:557-560.

-6 Bruce S, Hannula-Jouppi K, Peltonen J, Kere J, Lipsanen-Nyman M: Clinically distinct epigenetic subgroups in Silver-Russell syndrome: the degree of H19 hypomethylation associates with phenotype severity and genital and skeletal anomalies. J Clin Endocrinol Metab 2009;94:579-587.

7 Falkert A, Dittmann K, Seelbach-Gobel B: Silver-Russell syndrome as a cause for early intrauterine growth restriction. Prenat Diagn 2005;25:497-501.

-8 Feldmann M, Gilgenkrantz S, Parisot S, Zarini G, Marchal C: 3M dwarfism: a study of two further sibs. J Med Genet 1989;26:583585.

9 Hennekam RC, Bijlsma JB, Spranger J: Further delineation of the 3-M syndrome with review of the literature. Am J Med Genet 1987;28:195-209. 
10 Huber C, Dias-Santagata D, Glaser A, O'Sullivan J, Brauner R, Wu K, Xu X, Pearce K, Wang R, Uzielli ML, Dagoneau N, Chemaitilly W, Superti-Furga A, Dos Santos H, Megarbane A, Morin G, Gillessen-Kaesbach G, Hennekam R, Van der Burgt I, Black GC, Clayton PE, Read A, Le Merrer M, Scambler PJ, Munnich A, Pan ZQ, Winter R, CormierDaire V: Identification of mutations in CUL7 in 3-M syndrome. Nat Genet 2005;37:11191124.

11 Marik I, Marikova O, Kuklik M, Zemkova D, Kozlowski K: 3-M syndrome in two sisters. J Paediatr Child Health 2002;38:419-422.

-12 Mueller RF, Buckler J, Arthur R, Bonsor G, Dear P, Walters K, Towns GM: The 3-M syndrome: risk of intracerebral aneurysm? J Med Genet 1992;29:425-427.

13 Temtamy SA, Aglan MS, Ashour AM, Ramzy MI, Hosny LA, Mostafa MI: 3-M syndrome: a report of three Egyptian cases with review of the literature. Clin Dysmorphol 2006;15: 55-64.

14 van der Wal G, Otten BJ, Brunner HG, van der Burgt I: 3-M syndrome: description of six new patients with review of the literature. Clin Dysmorphol 2001;10:241-252.

15 Winter RM, Baraitser M, Grant DB, Preece MA, Hall CM: The 3-M syndrome. J Med Genet 1984;21:124-128.

16 Wollmann HA, Kirchner T, Enders H, Preece MA, Ranke MB: Growth and symptoms in Silver-Russell syndrome: review on the basis of 386 patients. Eur J Pediatr 1995; 154: 958-968.

17 Ounap K, Reimand T, Magi ML, Bartsch O: Two sisters with Silver-Russell phenotype. Am J Med Genet A 2004;131:301-306.

- 18 Binder G, Seidel AK, Martin DD, Schweizer R, Schwarze CP, Wollmann HA, Eggermann T, Ranke MB: The endocrine phenotype in silver-russell syndrome is defined by the underlying epigenetic alteration. J Clin Endocrinol Metab 2008;93:1402-1407.

19 Bartholdi D, Krajewska-Walasek M, Ounap $\mathrm{K}$, Gaspar H, Chrzanowska KH, Ilyana H, Kayserili H, Lurie IW, Schinzel A, Baumer A: Epigenetic mutations of the imprinted IGF2H19 domain in Silver-Russell syndrome (SRS): results from a large cohort of patients with SRS and SRS-like phenotypes. J Med Genet 2009;46:192-197.

-20 Eggermann T, Meyer E, Obermann C, Heil I, Schuler H, Ranke MB, Eggermann K, Wollmann HA: Is maternal duplication of 11p15 associated with Silver-Russell syndrome? J Med Genet 2005;42:e26.

21 Gicquel C, Rossignol S, Cabrol S, Houang M, Steunou V, Barbu V, Danton F, Thibaud N, Le Merrer M, Burglen L, Bertrand AM, Netchine I, Le Bouc Y: Epimutation of the telomeric imprinting center region on chromosome 11p15 in Silver-Russell syndrome. Nat Genet 2005;37:1003-1007.

22 Eggermann T: Silver-Russell and Beckwith-Wiedemann syndromes: opposite (epi)mutations in $11 \mathrm{p} 15$ result in opposite clinical pictures. Horm Res 2009;71(suppl 2):30-35.

23 Eggermann $\mathrm{T}$, Zerres K, Eggermann K, Moore G, Wollmann HA: Uniparental disomy: clinical indications for testing in growth retardation. Eur J Pediatr 2002;161: 305-312.

24 Hanson D, Murray PG, Sud A, Remtamy SA, Aglan M, Superti-Furga A, Holder SE, Urquhart J, Hilton E, Manson FDC, Scambler P, Black GCM, Clayton PE: The primordial growth disorder 3-M syndrome connects ubiquitination to the cytoskeletal adaptor OBSL1. Am J Hum Genet 2009;84:801-806.

25 Maksimova N, Hara K, Miyashia A, Nikolaeva I, Shiga A, Nogovicina A, Sukhomyasova A, Argunov V, Shvedova A, Ikeuchi T, Nishizawa M, Kuwano R, Onodera O: Clinical, molecular and histopathological features of short stature syndrome with novel CUL7 mutation in Yakuts: new population isolate in Asia. J Med Genet 2007;44:772-778.

26 Le Merrer M, Brauner R, Maroteaux P Dwarfism with gloomy face: a new syndrome with features of 3-M syndrome. J Med Genet 1991;28:186-191.

-27 Hanson D, Murray PG, O’Sullivan J, Urquhart J, Daly S, Bhaskar SS, Biesecker LG, Skae M, Smith C, Cole T, Kirk J, Chandler K, Kingston H, Donnai D, Clayton PE, Black GCM: Exome sequencing identifies CCDC8 mutations in 3-M syndrome, suggesting that CCDC8 contributes in a pathway with CUL7 and OBSL1 to control human growth. Am J Hum Genet 2011;89:148-153.

28 Huber C, Delezoide AL, Guimiot F, Baumann C, Malan V, Le Merrer M, Da Silva DB, Bonneau D, Chatelain P, Chu C, Clark R, Cox H, Edery P, Edouard T, Fano V, Gibson K, Gillessen-Kaesbach G, Giovannucci-Uzielli ML, Graul-Neumann LM, van Hagen JM, van Hest L, Horovitz D, Melki J, Partsch CJ, Plauchu H, Rajab A, Rossi M, Sillence D, Steichen-Gersdorf E, Stewart H, Unger S, Zenker M, Munnich A, Cormier-Daire V: A large-scale mutation search reveals genetic heterogeneity in $3 \mathrm{M}$ syndrome. Eur J Hum Genet 2009;17:395-400.

29 Dias DC, Dolios G, Wang R, Pan ZQ: CUL7: a DOC domain-containing cullin selectively binds Skp1.Fbx29 to form an SCF-like complex. Proc Natl Acad Sci USA 2002;99:1660116606.

30 Willems AR, Schwab M, Tyers M: A hitchhiker's guide to the cullin ubiquitin ligases: SCF and its kin. Biochim Biophys Acta 2004; 1695:133-170.

31 Arai T, Kasper JS, Skaar JR, Ali SH, Takahashi C, DeCaprio JA: Targeted disruption of p185/cul7 gene results in abnormal vascular morphogenesis. Proc Natl Acad Sci USA 2003;100:9855-9860.

-32 Tsunematsu R, Nishiyama M, Kotoshiba S, Saiga T, Kamura T, Nakayama KI: Fbxw8 is essential for Cul1-Cul7 complex formation and for placental development. Mol Cell Biol 2006;26:6157-6169.
-33 Tsutsumi T, Kuwabara H, Arai T, Xiao Y, Decaprio JA: Disruption of the Fbxw8 gene results in pre- and postnatal growth retardation in mice. Mol Cell Biol 2008;28:743-751.

34 Sarikas A, Xu X, Field LJ, Pan ZQ: The cullin7 E3 ubiquitin ligase: a novel player in growth control. Cell Cycle 2008;7:3154-3161.

35 Okabe H, Lee SH, Phuchareon J, Albertson DG, McCormick F, Tetsu O: A critical role for FBXW8 and MAPK in cyclin D1 degradation and cancer cell proliferation. PLoS One 2006; 1:e128.

>36 Xu X, Sarikas A, Dias-Santagata DC, Dolios G, Lafontant PJ, Tsai SC, Zhu W, Nakajima H, Nakajima HO, Field LJ, Wang R, Pan ZQ: The CUL7 E3 ubiquitin ligase targets insulin receptor substrate 1 for ubiquitin-dependent degradation. Mol Cell 2008;30:403-414.

>37 Alao JP: The regulation of cyclin D1 degradation: roles in cancer development and the potential for therapeutic invention. Mol Cancer 2007;6:24.

$>38$ Lin DI, Barbash O, Kumar KG, Weber JD, Harper JW, Klein-Szanto AJ, Rustgi A, Fuchs SY, Diehl JA: Phosphorylation-dependent ubiquitination of cyclin D1 by the SCF (FBX4-alphaB crystallin) complex. Mol Cell 2006;24:355-366

39 Dearth RK, Cui X, Kim HJ, Hadsell DL, Lee AV: Oncogenic transformation by the signaling adaptor proteins insulin receptor substrate (IRS)-1 and IRS-2. Cell Cycle 2007;6: 705-713.

40 Kaustov L, Lukin J, Lemak A, Duan S, Ho M, Doherty R, Penn LZ, Arrowsmith CH: The conserved $\mathrm{CPH}$ domains of Cul7 and PARC are protein-protein interaction modules that bind the tetramerization domain of p53. J Biol Chem 2007;282:11300-11307.

41 Andrews P, He YJ, Xiong Y: Cytoplasmic localized ubiquitin ligase cullin 7 binds to p53 and promotes cell growth by antagonizing p53 function. Oncogene 2006;25:45344548.

42 Jung P, Verdoodt B, Bailey A, Yates JR 3rd, Menssen A, Hermeking H: Induction of cullin 7 by DNA damage attenuates p53 function. Proc Natl Acad Sci USA 2007;104: 11388-11393.

43 Kasper JS, Arai T, DeCaprio JA: A novel p53binding domain in CUL7. Biochem Biophys Res Commun 2006;348:132-138.

$\checkmark 44$ Kim SS, Shago M, Kaustov L, Boutros PC, Clendening JW, Sheng Y, Trentin GA, Barsyte-Lovejoy D, Mao DY, Kay R, Jurisica I, Arrowsmith CH, Penn LZ: CUL7 is a novel antiapoptotic oncogene. Cancer Res 2007;67: 9616-9622.

45 Huber C, Fradin M, Edouard T, Le Merrer M, Alanay Y, Da Silva DB, David A, Hamamy H, van Hest L, Lund AM, Michaud J, Oley C, Patel C, Rajab A, Skidmore DL, Stewart H, Tauber M, Munnich A, Cormier-Daire V: OBSL1 mutations in 3-M syndrome are associated with a modulation of IGFBP2 and IGFBP5 expression levels. Hum Mutat 2010; 31:20-26. 
-46 Geisler SB, Robinson D, Hauringa M, Raeker MO, Borisov AB, Westfall MV, Russell MW: Obscurin-like 1, OBSL1, is a novel cytoskeletal protein related to obscurin. Genomics 2007;89:521-531.

-47 Hsieh CM, Fukumoto S, Layne MD, Maemura K, Charles H, Patel A, Perrella MA, Lee ME: Striated muscle preferentially expressed genes alpha and beta are two serine/ threonine protein kinases derived from the same gene as the aortic preferentially expressed gene-1. J Biol Chem 2000;275: 36966-36973.

-48 Sutter SB, Raeker MO, Borisov AB, Russell MW: Orthologous relationship of obscurin and Unc-89: phylogeny of a novel family of tandem myosin light chain kinases. Dev Genes Evol 2004;214:352-359.
49 Fukuzawa A, Lange S, Holt M, Vihola A, Carmignac V, Ferreiro A, Udd B, Gautel M: Interactions with titin and myomesin target obscurin and obscurin-like 1 to the M-band: implications for hereditary myopathies. J Cell Sci 2008;121:1841-1851.

50 Pernigo S, Fukuzawa A, Bertz M, Holt M, Rief M, Steiner RA, Gautel M: Structural insight into M-band assembly and mechanics from the titin-obscurin-like-1 complex Proc Natl Acad Sci USA 2010;107:29082913.

-51 Sauer F, Vahokoski J, Song YH, Wilmanns M: Molecular basis of the head-to-tail assembly of giant muscle proteins obscurinlike 1 and titin. EMBO Rep 2010;11:534-540.
2 Araki E, Lipes MA, Patti ME, Bruning JC, Haag B 3rd, Johnson RS, Kahn CR: Alternative pathway of insulin signalling in mice with targeted disruption of the IRS-1 gene. Nature 1994;372:186-190.

53 Cho H, Thorvaldsen JL, Chu Q, Feng F, Birnbaum MJ: Akt1/PKBalpha is required for normal growth but dispensable for maintenance of glucose homeostasis in mice. J Biol Chem 2001;276:38349-38352.

54 Liu JL, LeRoith D: Insulin-like growth factor I is essential for postnatal growth in response to growth hormone. Endocrinology 1999; 140:5178-5184.

55 Hershko DD: Oncogenic properties and prognostic implications of the ubiquitin ligase Skp2 in cancer. Cancer 2008;112:14151424. 